\title{
Information Network Construction on the Inheritance of Central Plains Martial Arts
}

\author{
---As an Intangible Cultural Heritage
}

\author{
Li Yongzhi \\ Luoyang normal univetsity,Henan,China \\ e-mail:liyongzhi2000@163.com
}

\author{
Yin Tenglong \\ Luoyang normal univetsity,Henan,China \\ e-mail:yintenglong1980@163.com
}

\begin{abstract}
The development and inheritance of Central Plains martial arts, as an intangible cultural heritage, is in a difficult period. But the advantages of information networking technology, such as fast transmission, wide audience, strong interactivity, and rich information have provided a new technical means for the development of martial arts. In order to achieve the sustainable development of the intangible cultural heritage---Central Plains martial arts, it is necessary to build an integrated information network platform for Henan martial arts, and actively push on the development and utilization of Central Plains martial arts.
\end{abstract}

Keywords: Central Plains martial arts; intangible cultural heritage; information; network

\section{THE DEVELOPMENT STATUS OF INTANGIBLE CULTURAL HERITAGE---CENTRAL PLAINS MARTIAL ARTS}

The development of traditional martial arts has always been concerned by academics, and it is also a pending and urgent proposition. The Central Plains martial arts culture is an important part of Chinese traditional culture and the precious cultural heritage, and a wide range of Central Plains martial arts has a long history and farreaching influence. According to investigation of Henan university professor Han, in the central region, there are more than 40 species of boxing system, with an orderly source and integral system. Such as Shaolin boxing, Chen's tai chi boxing have been known around the world, and also resounded in the country. The widespread 25 species of boxing, such as Chang-style boxing, mind Liuhe boxing, Gassan Eight Extremes boxing, yellow school boxing, arm fist boxing, and plum flower boxing have been included in the national and provincial intangible cultural heritage list. The reason why these boxing are listed in the national intangible cultural heritage is that these boxing have prominent value and outstanding representative. However, Central Plains martial arts are facing the dilemma of existence, with the improvement of science and technology, people spend much time on making money and following the fads, and fewer and fewer people would like to spend time on specializing in martial arts training. Modern western sports has a huge impact on the traditional Chinese martial arts, and the intrusion of exotic sports culture makes the Chinese martial arts culture market get smaller and smaller.

As with the material cultural heritage, intangible cultural heritage has been passed on by a living way to achieve its historical cognitive value and significance. Most fundamentally, the national cohesion comes from cultural identity, the Central Plains martial arts culture plays an important role in the inheritance of Chinese civilization, especially in the inheritance of the Chinese moral civilization, the enhancement of national selfconfidence and national cohesion. The cultural heritage protection of the Central Plains martial arts is not only to meet the need of understanding history, but also to create new literature, new art, and new technologies. "Cultural" diversity creates a rich and varied world, and different Central Plains martial arts genre itself is the performance of the Chinese cultural diversity. To some extent, the protection of Central Plains martial arts is to protect the diversity of Chinese culture.

\section{THE ISSUES ENCOUNTERED IN THE DEVELOPMENT OF INTANGIBLE CULTURAL HERITAGE---CENTRAL PLAINS MARTIAL ARTS}

\section{A. Propagation of Central Plains Martial Arts Culture}

The inheritance of Central Plains martial arts as an intangible cultural heritage mainly includes content, means, methods, and inheritors four aspects. With the changing times, people's cognitive styles, living habits, means of information transmission have undergone tremendous changes, the environment and the soil to the survival of traditional martial arts as an intangible cultural heritage also has gradually subsided. The inheriting characteristics of traditional martial arts has shown its frailty, long-term character, the nature of learning from teachers, and non-standardness, which cannot adapt to the new period of social development, causing the problems about inheritance of traditional martial arts.

\section{B. Protection of Central Plains Martial Arts Culture}

The development of Central Plains martial arts as an intangible cultural heritage has a strong public warfare, and its concrete performance is in three aspects: big 
investment, long cycle, and low benefits. It is prone to the unclear power and responsibility and uneasy to protect the property rights, besides, its attractiveness of the commercial capital is limited. In the development of Central Plains traditional martial arts, Shaolin culture and tai chi culture have been relatively successful example, however, Shaolin and tai chi intellectual property have suffered from serious violation, so Shaolin temple property protection should be put in the first place. Compared to the Shaolin and Tai Chi, other underdeveloped martial arts boxing also face this problem. Therefore, the government should play an active role in the protection of intangible cultural heritage, and sports-related departments also need to dedicate in the protection of intangible cultural heritage, to open a wider space for the protection and development of national traditional sports.

\section{Development and Utilization of Central Plains Martial Arts Culture}

Martial arts is a intangible cultural heritage, how to ensure its inheritance on the basis of authenticity and integrity, blending with modern culture, and keeping reasonable in development and utilization, is the key to realize sustainable survival for sustainable development of martial arts. While emphasizing the protection of intangible cultural heritage, we must have an idea of economic development, and also the mind and consciousness of "through the development to promote protection". In the development process of intangible cultural heritage resources, fully exploring the cultural values and tourism development of Central Plains martial arts, and realizing the scientific and rational planning and utilization, not only can maximize the use of martial arts' s commercial value, but keep its integrity and authenticity.

\section{DEVELOPMENT OPPORTUNITIES OF CENTRAL MARTIAL ARTS AS INTANGIBLE CULTURAL HERITAGE IN THE INFORMATION NETWORK ERA}

The implementation of the intangible cultural heritage protection work provides an excellent opportunity for the protection and inheritance of the Central Plains martial arts culture, five kinds of Henan martial arts boxing have been named state-level intangible cultural heritage, and 19 kinds of martial arts boxing named provincial intangible cultural heritage. How to make more and more people realize the importance and urgency of protecting the central plains martial arts culture, and actively participate in the project are what we need to solve. Network era provides us with a broad platform. In 2015, the Internet users have reached over 600 million, such a broad audience makes full use of information network platform for the inheritance and development of traditional martial arts. Based on information network platform, with its advantages of fast transmission, wide audience, strong interactivity, mass information, we are excavating, sorting, protecting and promoting the endangered traditional martial arts in Henan. In view of this, from the perspective of protection on intangible cultural heritage, doing a research of information network construction on the Central Plains martial arts has an outstanding value and far-reaching significance on promoting the sustainable development of the Central Plains martial arts.

At present, Henan province has 65 martial arts class website, most of which are the spread of Chen's tai chi, Shaolin martial arts and strong commerciality private school website, but few are Comprehensive Academic website conducted for inheritance and protection of the Central Plains martial arts culture, which is against to the protection and development of the Central Plains martial arts culture. The advantage of development and construction of information network platform for Central Plains martial arts is to protect, excavate, and inherit the "intangible" martial arts boxing, and use the platform to improve the environmental quality of "intangible" martial arts, shaping a martial arts brand. To change the environment and conditions of the "intangible" martial arts, it is necessary to deal with the resource integration of "intangible". Therefore, we should rely on the Central Plains, from the perspective of national traditional sports and information technology, study systematically on the main forms and contents of information network transmission over the perspective of intangible cultural heritage protection, lay the theoretical foundation of information network for the construction of the Central Plains martial arts, contribute to enrich martial arts boxing theory, and expand new field of research, new perspectives for the traditional martial arts network, forming a new theory;

\section{COUNTERMEASURES AND SUGGESTIONS}

\section{A. Construction of an Integrated Information Network Platform of Martial Arts in Henan Province}

In the 21st century, Information network era has become a global survival mode, and the resource information in all social sectors and fields through the Internet has achieved information integration, dispose, and sharing, making it achieve rapid development. Network transmission can have a rapid development in a short period, mainly by its advantages and characteristics different from the traditional media decision. The speed and scale of the network transmission information, the affected geographical scope, and the manifestation have far surpassed the conventional mass media, which has greatly broadened people's horizons and enriched people's cultural lives. Network communication mainly has the following advantages: large amount of information, speed, diverse transmission means, multi-directional interactive communication process, the dominant position of the audience, open exchanges, wide dissemination of the body and so on. Modernization of Central Plains traditional martial arts should take full advantages of the characteristics of the inheritance and development of information network platform. At present, the information network platform of traditional martial arts in Henan province also has many problems. Although a large number of relevant websites about Henan province's 
martial arts have been searched by most people, most of them are single boxing sites such as Shaolin boxing or Chen-style tai chi and the recruitment propaganda sites of folk martial arts school; The official website of "Martial Arts Network of Henan" mainly release the information of related events announcements and related information sheets about martial arts; The martial arts websites of current universities are restricted to the introduction of professional and faculty, the basic theoretical knowledge of martial arts, without showing the advantages of academic resources. Analysis of these sites, they still lack comprehensive information of promoting the Central Plains martial arts, the protection and inheritance of "intangible" boxing, the history of the Central Plains martial arts, the cultural studies of Central Plains martial arts, etc., which can not meet the needs of different groups to the Central Plains martial arts. Therefore, according to education, management, sociology, information classification principles to analyze the realistic value of information network on traditional martial arts, combine with the knowledge of technical aspects on modern information technology, network technology, multimedia technology, website development technology, database technology and so on, it is possible to elaborate the realization way of information network construction on Central Plains martial arts culture from the perspective of intangible cultural heritage protection. Starting from the collected information resources, protection, inheritance, development and other aspects of "Intangible" martial arts boxing, having a deep inquiry of value, and realizing foundation and approach to information network construction on building the Central Plains traditional martial arts culture, on this basis, building the information network application platform of central plains martial arts , it is also likely to promote the sustainable development of martial arts, and expand external influence of Central Plains martial arts culture.

At present, the protection of traditional culture is a contemporary issue, and a long-term system engineering. Firstly, the protection of national traditional culture should be raised to legal height; Secondly, we should have a sense of historical responsibility for the protection of traditional culture and long-term adherence; Thirdly, with this correspondence, the protection of traditional culture is a historic task, so we must resolutely abandon the quick success of fickleness, scientifically formulate a long-term conservation planning, and carefully implement it. For example: Japan makes full use of the rapid development of modern information network technology, accelerating the process of the ethnic traditional sports information network. Besides, Japan has launched a website sports museum to support the retrieval of traditional sports collection information under the network environment. At the same time, supporting interactive Web browsing, editing, giving full play to the advantages of information network technology, and protecting the national traditional sports. Japan has formed a relatively perfect system of information collection, processing, storage and usage, and also has a comprehensive database for its citizens to provide sports information and related services.

\section{B. Research and Exploitation of the Central Plains Martial Arts as an Intangible Cultural Heritage}

With the development of our country's economy, the Internet has been showing its great power, but the network dissemination being used in the information network construction of traditional martial arts is still in a primary stage of development as a whole. At present, the academia for the traditional martial arts and network communication has achieved a lot of research and analysis, and has obtained the certain theoretical achievements, mainly in the following two aspects:

- Enhancement of Basic Research on Information Network of Martial Arts

Starting the research from the function of information network development of martial arts, the values, the nature and types, characteristics, network martial arts culture can be divided into four types: website martial arts culture, forum martial arts culture, video martial arts culture, and blogs martial arts culture. Combined with the current situation of the Central Plains martial arts, from different types of characteristics, we should have targeted development and application to them. Secondly, we should start from the application of the martial arts information network, from the present situation of the development of martial arts information network and its existing problems, moreover, focus on feasibility, market, operation mode, standardization and other aspects. In the era of information network, we should make assessment and analysis on business value of Central Plains martial arts resources, make development plan, and also make full use of the high quality resources of the central plains martial arts as intangible cultural heritage, so as to expand markets, form the brand effect, point to an area, and enhance the overall development and utilization of martial arts and cultural resources.

- $\quad$ Enhancement of the Development and Application on Information Technology in the Central Plains Martial Arts

The information applications in sports field, the development and utilization of system construction research and sports information resources have been achieved a leading position, these research ideas and achievements are worthy of learning and using for reference. The inheritance, protection and development of traditional martial arts as intangible cultural heritage has made certain achievements, especially in the the promotion and dissemination of Shaolin and tai chi. Therefore, in the process of sustainable development of the Central Plains martial arts as intangible cultural heritage, it is necessary to build information network platform entity, to achieve the greatest social achievements, and reach purposes of the heritage and protection on Central Plains traditional martial arts culture. At the same time, it is necessary to create a more efficient and more perfect cultural heritage protection model to promote the vigorous development of the Central Plains martial arts. 


\section{REFERENCES}

[1] CHEN qing. Wushu modern means of communication[J]. Wushu Science, 2010(12):1-3

[2] LIU Peng, SUN Gang. Perplexity and Reflection on Modernized Development of Wushu[J]. Journal of Shanghai University of Sport, 2008(5):71-74

[3] XU Cai-tong. Modernization and Transformation of traditional Chinese sports[J]. Journal of Wuhan Institute of Physical Education. 2008(4):61-64

[4] WANG Gang, GUO Hai-zhou. Establishment of Modern Standard System of Chinese Wushu[J]. Journal of Xi'an Physical Education University. 2007(1):1-6

[5] http://www.dahe.cn/xwzx/zt/hnzt/2007khn/xcj/t20070416_929403. htm

[6] Zhou, Lanjun. A research on the development of information network among China and developed countries [J].Journal of Guangzhou Sport University, 2003(6).

[7] Huang, Yingping. A survey and strategy on the market of information network of Henan martial arts[J]. Journal of Boji, 2006(10)

[8] Xing, Xiangping. A study on the construction of database platform of Zhao culture $[\mathrm{J}]$. Journal of Handan Polytechnic College, 2007(4).

[9] Li, Jie. A survey on the resources of martial arts in Henan[J]. Journal of Zhonghua Martial Arts, 2007(8).

[10] MA Liya. The Social Value and Cultural Choice of National Traditional Sports Development under Sociological Perspective[J]. Journal of Sports and Science, 2012(2): 80-83 